INVITED ARTICLE

\title{
Rodenticide Poisoning
}

\author{
Carol D'Silva ${ }^{1}$, Bhuvana Krishna ${ }^{2}$
}

Keywords: Aluminium/zinc phosphide, Hydroxycoumarins, Rodenticide, Yellow phosphorous.

Indian Journal of Critical Care Medicine (2019): 10.5005/jp-journals-10071-23318

\section{INTRODUCTION}

Rodenticides, commonly referred to as "rat poisons," are chemical agents aimed at eliminating small rodents. The common targets for their use are household rodents i.e. rats/mice, squirrels, gophers, etc. Controlling rodents is imperative as they are vectors for spread of disease, destroy crops/grains, and multiply rapidly.

India being a primarily agrarian country, rodenticides are widely used and also freely available. They are available in various formulations as powders, pastes, pellets, cereal baits, or blocks. Developing a rodenticide has its challenges as rodents do not feed on what appears to be toxic to them (primary bait refusal) and do not feed twice on what they suspect to be poisonous (bait shyness). An ideal rodenticide is one that is highly toxic to rodents in small quantities, nontoxic to nontarget species, and avoids bait shyness and bait refusal.

Rodenticides are classified based on their toxicity as following (refer Table 1):

- Highly toxic: Median lethal dose (LD 50) ranging from 0 to 50 $\mathrm{mg} / \mathrm{kg}$ body weight

- Moderately toxic: LD 50 ranging from 50 to $500 \mathrm{mg} / \mathrm{kg}$

- Less toxic: LD $50 \geq 500 \mathrm{mg} / \mathrm{kg}$

In this review, we shall focus on the three main classes of rodenticides, commonly incriminated as agents of poisoning in the Indian subcontinent. They include yellow/white phosphorous, metal phosphides, and 4-hydroxycoumarin derivatives.

\section{Epidemiology}

The global burden of rodenticide poisoning varies from region to region. In the United States, as per the American Association of Poison Control Centers, rodenticides accounted for $0.3 \%$ of 2.3 million human exposures as reported to the regional poison control centers. ${ }^{1}$ The most common agents implicated were the 4-hydroxycoumarins, followed by bromethalin, warfarin, and metal phosphides.

In India, however, the common agents implicated are the metal phosphides, particularly aluminium phosphide. In a retrospective study done in PGI, Chandigarh, aluminium phosphide constituted $26.1 \%$ of all pesticide poisoning from 1990 to $2004 .{ }^{2}$ The case fatality was highest with aluminium phosphide poisoning. However, they did note a decline in mortality secondary to this agent over the years. The National Poison Information Centre (NPIC) is a roundthe-clock telephone service meant for dissemination of information regarding the symptoms and management of various poisonings. It is managed by the Department of Pharmacology at the All India Institute of Medical Sciences (AIIMS). In a retrospective study, data over 13 years were analyzed from the NPIC. Of 14,867 cases reported to the NPIC, $17.06 \%$ were due to rodenticides. ${ }^{3}$ They also
1,2Department of Critical Care Medicine, St. John's National Academy of Health Sciences, Bengaluru, Karnataka, India

Corresponding Author: Carol D'Silva, Department of Critical Care Medicine, St. John's National Academy of Health Sciences, Bengaluru, Karnataka, India, Phone: +91 9766397569, e-mail: calps80@gmail.com How to cite this article: D'Silva C, Krishna B. Rodenticide Poisoning. Indian J Crit Care Med 2019;23(Suppl 4):S272-S277.

Source of support: Nil

Conflict of interest: None

observed a rise in poisonings due to rodenticides as compared to organophosphate compounds. Poisoning by household pesticides, including rodenticides, superseded those by agricultural pesticides. In Southeast Asian and South American countries, consumption of yellow phosphorous containing fireworks has been a major cause of poisoning. ${ }^{4-6}$

\section{Mode of Poisoning}

- Ingestion-This is the most common mode reported. It may be accidental or intentional. Accidental consumption is more commonly noted in the pediatric age group.

- Inhalation-This is especially seen with phosphine gas that is produced as a result of metal phosphides reacting with water.

- Dermal route-Although very rare, poisoning by this route has also been reported.

\section{General Approach to Rodenticide Poisoning}

It is important to identify the compound as the clinical manifestations and treatment required vary. It is encouraged to contact the

Table 1: Classification of rodenticides based on toxicity with examples

\begin{tabular}{ll}
\hline Highly toxic agents & Strychnine \\
& Thallium \\
& Elemental phosphorous \\
& Metal phosphides \\
& Sodium monofluoroacetate \\
& Arsenic \\
Moderately toxic agents & Alpha-naphthyl thiourea \\
Less toxic agents & Cholecalciferol \\
& Warfarin \\
& Superwarfarins-brodifacoum, \\
& bromadiolone, chlorophacinone, \\
& difenacoum, and diphacinone \\
& Bromethalin \\
& Red squill \\
\hline
\end{tabular}


National Poison Information Centre, managed by the All India Institute of Medical Sciences, which documents and provides information regarding management of poisoning round the clock.

The route of ingestion and dose should be enquired; however, in cases of deliberate self-harm, this information may be difficult to obtain.

Caution is exercised with regards to gastric lavage in metal phosphides poisoning as it may lead to further liberation of phosphine gas endangering the medical professionals. Activated charcoal may be used to retard absorption of the agents.

All patients should be managed in an intensive care unit with close monitoring. Clinical manifestations may not be seen immediately at presentation and may develop over 48-72 hours.

\section{Yellow Phosphorous Poisoning}

Yellow or white phosphorous is a waxy substance and is commonly used in fertilizers, fireworks, ammunition, and rodenticide preparations. It is known to have a garlic-like odor. RATOL is a popular brand of yellow phosphorous freely available in India. It is available as pastes containing $2-5 \%$ of yellow phosphorous.

Yellow phosphorous poisoning is common in children as the paste is mistaken for toothpaste, or bread smeared with this paste as bait could be accidentally consumed., ${ }^{7,8}$

Ingestion of fireworks is another common mode of poisoning in Southeast Asia, commonly seen in children and young adults. ${ }^{5}$

\section{Mechanism of Action}

Yellow phosphorous is a protoplasmic toxin affecting the hepatic, gastrointestinal, cardiovascular, and renal systems. It is slowly absorbed through the gastrointestinal tract, and respiratory mucosa and serum phosphorous levels quickly rise post consumption. It is believed to affect ribosomal function and protein synthesis and cause impaired glucose homeostasis and impaired lipoprotein and triglyceride metabolism leading to fatty degeneration of liver, kidney, and brain., ${ }^{9,10}$ Hypocalcemia can also occur due to binding of calcium with the excessive phosphorous in the blood.

The lethal dose is around $1 \mathrm{mg} / \mathrm{kg}^{11}$ and fulminant poisoning occurs with doses exceeding 1-2 g. Rubitsky and Myerson ${ }^{12}$ in 1949 have described three stages through which the clinical manifestations progress after ingestion of yellow phosphorus.

In the first 24 hours post ingestion, patients present with mild symptoms such as nausea and vomiting due to gastrointestinal irritation. In the next 24-72 hours, patients may remain asymptomatic. There may be a rise in bilirubin levels and liver enzymes at this stage. After 72 hours, they can manifest with acute liver failure (ALF), coagulopathy, hypotension, cardiac arrythmias, and acute kidney injury. Central nervous system involvement occurs as confusion, psychosis, hallucinations, and coma. Hollow viscus perforation has also been reported following its ingestion. ${ }^{13}$ With regards to hepatobiliary involvement, clinical features range from mild transaminitis to fulminant live failure. Luminescent feces and vomitus, with or without a garlic-like odor, has also been described. ${ }^{11,14}$ Death occurs usually due to cardiovascular collapse or complications of acute liver failure.

\section{Treatment}

There is no specific diagnostic test and measuring serum phosphorous levels is not entirely useful in estimating the possible amount of toxin consumed. ${ }^{15}$

There is no known antidote for yellow phosphorous poisoning.
Initial treatment includes decontamination and supportive therapy.

Gastric lavage with 1:1000 potassium permanganate solution is done to retard further absorption as it oxidizes phosphorus into relatively less toxic phosphoric acid and phosphates. Lavage with saline can also be done.

These patients should be monitored in an intensive care unit and followed up with daily liver and renal function tests.

Use of $\mathrm{N}$-acetyl cysteine is well documented for paracetamol poisoning and has also been studied in other causes of acute liver failure. ${ }^{16,17}$ Case reports and case series following rodenticide poisoning have shown that $N$-acetyl cysteine may be useful in cases of rodenticide-induced ALF but further evidence is needed. ${ }^{18}$

Liver transplantation has also been done in certain cases of ALF. ${ }^{15}$

Role of intravenous corticosteroids and exchange transfusions has been studied. ${ }^{19}$ Although this study had a small sample size, he demonstrated that corticosteroids were not useful and in fact may be more harmful in cases of yellow phosphorous poisoning. Although some benefit was seen in patients who received exchange transfusion for grade IV hepatic encephalopathy, the study was not sufficiently powered to establish significance in these cases.

\section{Aluminium and Zinc Phosphide Poisoning}

Phosphides are the commonest agent responsible for rodenticide poisoning in India. Metal phosphides are commonly used to keep grains stored in silos, godowns, or during transport rodent free. They react with moisture in the air to release phosphine that is an active pesticide by itself. They are popular rodenticides as they are highly potent, generally inexpensive, and do not leave toxic residue on grains.

They are available as aluminium, zinc, magnesium, or calcium salts in the form of tablets, pellets, or discs. Aluminium phosphide is available as dark yellow or dark grey crystals, while zinc phosphide is a grey crystalline powder.

In developing countries, aluminium phosphide is used extensively as a grain fumigant and as a rodenticide. Aluminium phosphide toxicity is particularly dangerous when consumed from a freshly opened or recently packed container. ${ }^{20}$ The mortality due to zinc phosphide ranges anywhere between $37 \%$ and $100 \%{ }^{21}$

\section{Mode of Poisoning}

It can occur through ingestion: accidental or intentional and through inhalation of liberated phosphine. The dermal route is relatively rare. ${ }^{22}$ In India, poisoning by phosphides is more often due to ingestion rather than accidental inhalation. Close proximity to the gas once released is not necessary to cause poisoning as it is heavier than air and can travel a certain distance. ${ }^{23}$

\section{Mechanism of Action}

The phosphides react with hydrochloric acid and water to release phosphine gas. The reaction is far stronger with acid than water. Pure phosphine is usually a colorless and odorless gas. Phosphine inhibits cytochrome $C$ oxidase, an essential enzyme in mitochondrial oxidative phosphorylation. However, it has been noted that this mechanism is demonstrated well in vitro, but seen in a lesser extent in vivo in humans and rodents. ${ }^{23}$ Other possible mechanisms have been studied. It is postulated that phosphine affects the mitochondrial morphology, inhibiting oxidative respiration, and causes a severe drop in mitochondrial 
membrane potential following exposure. Phosphine reacts with hydrogen peroxide to form the highly reactive hydroxyl radical that causes lipid peroxidation leading to oxidative damage of cellular membranes and cell death. ${ }^{22,23}$ Lipid peroxidation can occur due to direct inhibition of catalase and peroxidase. It also causes denaturation of enzymes involved in cellular respiration and metabolism. Interestingly, it has been noted to inhibit cholinesterases in vitro; however, the clinical relevance of this mechanism is questionable. ${ }^{24}$ The metal moiety of the compound can also contribute to toxicity indirectly.

\section{Toxikinetics}

Once phosphine is released in the stomach, it is rapidly absorbed from the gastrointestinal tract, enters the bloodstream, and reaches the liver, kidney, and brain. Most of the phosphine is excreted unchanged by the lungs while some of it is changed to phosphite and hypophosphite ions that are excreted in urine.

In vitro it has been seen to bind with hemoglobin irreversibly to form hemichrome, a methemoglobin derivative.

\section{Clinical Features}

Manifestations of phosphide toxicity appear rapidly, usually presenting within 30 minutes following exposure. Early features include nausea, vomiting, and epigastric pain due to the corrosive nature of phosphides. There may be a garlic odor in the breath of these patients. Phosphine gas emitted from emesis and feces of affected patients can pose to be harmful for the treating team and should be handled and discarded with appropriate precautions.

These features are rapidly followed by circulatory collapse, hypotension, myocarditis, pericarditis, acute pulmonary edema, and congestive heart failure.

Echocardiography in these patients often reveal global hypokinesia of the left ventricle and depressed ejection fraction. ST-T changes and arrythmias are seen on the electrocardiogram. Acute renal failure, jaundice, transaminitis progressing to acute liver failure, and disseminated intravascular coagulation are also common. Following inhalation, chest tightness, headache, giddiness, lethargy, convulsions, and delirium may be seen. Circulatory failure is an important cause of death.

Studies have observed increased or decreased serum magnesium levels post poisoning with aluminium phosphide. ${ }^{25}$ However, some studies have shown that magnesium levels may be normal post poisoning. ${ }^{26}$

Hypokalemia and hypoglycemia can also occur frequently post poisoning.

\section{Treatment}

There is no known antidote for the treatment of phosphide poisoning. Treatment is mainly supportive. Owing to its predilection for multiorgan failure and associated high mortality, these patients are best managed in an ICU.

\section{Decontamination}

Gastric lavage is controversial in cases of phosphide poisoning as it can increase the rate of disintegration of the pesticide and increase toxicity. ${ }^{23}$

Vegetable oils, especially coconut oil for lavage, have been used in some case reports but there is insufficient evidence to back their use. $^{27,28}$ The use of vegetable oils has been postulated to reduce release of phosphine.
Similarly several reports have suggested the use of potassium permanganate for gastric lavage, ${ }^{23}$ although the evidence to back its use is lacking.

Activated charcoal is beneficial to reduce toxicity due to metal phosphide ingestion.

In case of poisoning through the inhalational route, the victims should be removed from the contaminated site and supplemental oxygen should be given if necessary.

\section{Supportive Treatment}

These patients should be monitored in an intensive care unit and closely observed daily for organ dysfunction. Treatment included mechanical ventilation, organ supportive therapy, use of vasoactive drugs, and correction of dyselectrolytemia and hypoglycemia when indicated.

$\mathrm{N}$-acetyl cysteine is now being used as a part of treatment regimens for ALF due to phosphide poisoning; however, a definite benefit on mortality is yet to be proven.

Liver transplant has also been done in patients progressing to ALF.

There are also experimental animal studies attempting to use pralidoxime for treatment. Although mean survival time has been seen to have increased in rats administered with $10 \mathrm{mg} / \mathrm{kg}$ of aluminium phosphide, studies are needed to study its benefit in humans. ${ }^{29}$

\section{Coumarins}

Much before warfarin was used in humans as an anticoagulant, it was used by a biochemist named Karl Link and his colleagues as a rodenticide in $1948 .^{30}$

Coumarins come closest to being an ideal rodenticide in that they are colorless, odorless, less toxic to nontarget species, and an antidote is available in case of accidental consumption.

Interestingly, Joseph Stalin, whose death remains a mystery, was thought to have been poisoned by warfarin.

Coumarins are hepatotoxic in rats; however, the toxicity is much less in humans.

Rodents quickly developed resistance to warfarin and by the 1970s newer compounds were developed. They include the 4-hydroxycoumarins and the indanedione derivatives, chlorophacinone, and diphacinone.

The second generation of the 4-hydroxycoumarin class of anticoagulants has been used as rodenticides due to their longer presence in the body and high potency, and are commonly referred to as "superwarfarins" or "long-acting" anticoagulant rodenticides (LAARs).

They include brodifacoum, difenacoum, bromadiolone, and flocoumafen.

Of these, brodifacoum is the most common active ingredient in commercially available rodenticides in the United States and is usually found in a $0.005 \%$ concentration.

Brodifacoum is 100 times more potent than warfarin with respect to anticoagulant effects. ${ }^{31}$

The median lethal dose is found to be $0.12-0.172 \mathrm{mg} / \mathrm{kg}$ via the oral route. ${ }^{32}$

\section{Mechanism of Action}

4-Hydroxycoumarin acts by inhibiting the activity of hepatic vitamin $\mathrm{K} 1$ epoxide reductase, the enzyme involved in the regeneration 
of the active form of vitamin $\mathrm{K}$, and thus preventing the gamma carboxylation of vitamin K-dependent blood clotting factors II (prothrombin), VII, IX, and X (see Fig. 1).

\section{Routes of Exposure}

Poisoning can occur through ingestion and rarely through inhalation or transcutaneous exposure.

Most poisoning cases are intentional; however, in children accidental ingestion is more common. They are frequently available as pastes or brightly colored baits mixed with cereal, which can be mistaken as nontoxic food. The Environmental Protection Agency has included addition of bitterants and indicator dyes to all anticoagulants to limit toxicity. ${ }^{33}$

Poisoning via the inhalational route has been reported in cases where cocaine and marijuana laced with superwarfarins are inhaled. The reason for doing so is that the metabolism of drugs of abuse is slowed by saturation of liver enzymes by the superwarfarins. ${ }^{34}$

The transdermal route is rare and there are case reports of bleeding diathesis following spillage of diaphacione over skin or clothing. ${ }^{35}$

\section{Clinical Manifestations}

The evidence of coagulopathy occurs $24-48$ hours post consumption once all the coagulation factors are depleted below $30 \%$ of normal (see Table 2).

It can also be delayed by hours to weeks depending on the nature of poisoning and dose. Mild-to-severe life-threatening hemorrhage can occur, which include mucocutaneous, gastrointestinal, genitourinary, and intracranial bleeds. These include epistaxis, hematuria, gastrointestinal bleeding, spontaneous ecchymoses, and hematomas. Intracranial bleeds are associated with a high mortality. ${ }^{34}$

\section{Vitzamin $\mathrm{K}$ epoxide reductase}

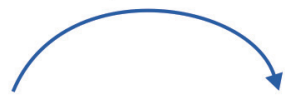

Oxidised Vitamin K epoxide (inactive)

Oxidised Vitamin $\mathrm{K}$ (active form)
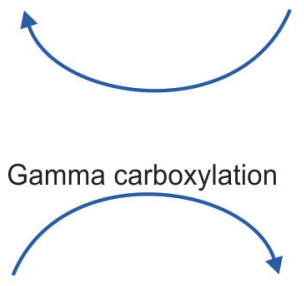

Factors II, VII, IX, $X$ (inactive)

Factors II, VII, IX, $\mathrm{X}$ (active)
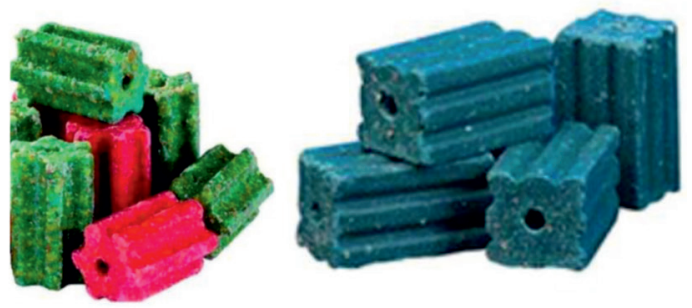

Fig. 1: Mechanism of action of anticoagulant class of rodenticides

\begin{tabular}{lc} 
Table 2: Mean half-lives of vitamin K-dependent coagulation factors & \\
\hline Coagulation factor & Mean half-life (hours) \\
\hline II (prothrombin) & 41 \\
VII & 6.2 \\
IX & 13.9 \\
X & 16.5 \\
\hline
\end{tabular}

Paradoxical thrombosis has also been reported following LAAR toxicity. This has been attributed to depletion of Protein $C$ and Protein $\mathrm{S}$, leading to an procoagulant state before other clotting factors are depleted. Cases of deep vein thrombosis and intracranial thrombosis have been reported as manifestations following LAAR poisoning. ${ }^{34}$

The half-life of brodifacoum is 16-34 days as compared to warfarin that has a half-life of 17-37 hours. Brodifacoum has been known to persist for 16-270 days post acute exposure. It has also been noted that even though serum levels may be low, the toxin may remain in the hepatic tissue, causing a persisting inhibition of vitamin $\mathrm{K}$ epoxide reductase. ${ }^{34}$

\section{Diagnosis}

Laboratory evidence of deranged prothrombin time (PT) and international normalized ratio (INR) commonly occurs 48 hours post exposure and can last for several days depending on the compound consumed. By the time the patient presents, PR and activated partial thromboplastin time (aPTT) are universally prolonged. Factor levels assays for factors II, VII, IX, X, and V can also be performed to help establish the diagnosis. These tests only indicate a possibility of LAAR poisoning. A high degree of suspicion is needed especially if not other cause for the coagulopathy is found. Delay in diagnosis is common especially in cases of unintentional consumption.

Confirmation can be done by measurement of 4-hydroxycoumarin levels in blood using high-performance liquid chromatography with tandem mass spectrometry. ${ }^{36}$ However, this may not be feasible always as this test is not available in most setups.

\section{Treatment}

The treatment is predominantly vitamin $\mathrm{K}$ supplementation. Fresh frozen plasma or prothrombin complex concentrates are needed in case of active bleeding.

Treatment with vitamin $\mathrm{K}$ maybe needed for several days to months. In a literature review, vitamin $\mathrm{K}$ supplementation was given from 28 to up to 730 days. ${ }^{37}$

Vitamin K-dependent clotting factors begin to increase within 6-8 hours post treatment. There is no clear consensus on the right dose to use. The initial dose of vitamin $\mathrm{K}$ used has varied from 0.1 to $3 \mathrm{mg} / \mathrm{kg} /$ day and doses as high as $500-800 \mathrm{mg} /$ day have also been used. ${ }^{34}$ Anaphylactic reactions can occur following vitamin $\mathrm{K}$ administration.

Misdiagnosis of these patients is common especially if they are initially asymptomatic. Children are often misdiagnosed to have hemophilia. Poisoning should be suspected in patients with prolonged multisite hemorrhage and with elevated PT and PTT, no signs of disseminated intravascular coagulation, and with no cause for factor inhibitor.

Patients need to be closely monitored following exposure for any signs of bleeding with daily follow-up PT/INR and PTT levels.

Therapeutic plasma exchange has also been studied in LAAR poisoning. Brodifacoum has a high protein binding and low volume of distribution, which makes it ideal for removal by plasma 
exchange. Studies have shown benefit of therapeutic plasma exchange in children following an anaphylactic reaction to vitamin $\mathrm{K}$ administered for brodifacoum poisoning. ${ }^{31}$

\section{Conclusion}

Rodenticide poisoning is an important health problem with a high case fatality rate especially with metal phosphides. Easy availability, over the counter or on e-commerce websites, and a lack of antidotes for rodenticides in our country pose an important health problem. Improving public awareness regarding their lethality and strict monitoring of sales and usage of rodenticides could help to avoid indiscriminate use and poisoning. The LAAR toxicity should be suspected especially in unexplained prolonged coagulopathy with no other incriminating cause.

\section{References}

1. Gummin DD, Mowry JB, Spyker DA, Brooks DE, Osterthaler KM, Banner W. 2017 Annual report of the American Association of Poison Control Centers' National Poison Data System (NPDS): 35th annual report. Clin Toxicol (Phila) 2018;56(12):1213. DOI: 10.1080/15563650.2018.1533727.

2. Murali R, Bhalla A, Singh D, Singh S. Acute pesticide poisoning: 15 years experience of a large north-west Indian hospital. Clin Toxicol 2009;47(1):35-38. DOI: 10.1080/15563650701885807.

3. Peshin SS, Srivastava A, Halder N, Gupta YK. Pesticide poisoning trend analysis of 13 years: a retrospective study based on telephone calls at the National Poisons Information Centre, All India Institute Of Medical Sciences, New Delhi. J Forensic Leg Med 2014;22:57. DOI: 10.1016/j.jlm.2013.12.013.

4. Gonzalez AF, Lopez PR. White phosphorus poisoning by oral ingestion of firecrackers or little devils: current experience in Ecuador. Clin Toxicol (Phila) 2011;49(1):29-33. DOI: 10.3109/15563650.2010. 547860.

5. Yüksekkaya H, Gumus M, Yucel A, Energin M, Demirci S. Ingestion of fireworks: rare cause of poisoning in children. Pediatr Emerg Care [Internet] 2019;35(3):216-219. DOI: 10.1097/PEC.0000000000001450.

6. Urbano-Fernandez O, Canizares L. Acute hepatotoxicity from ingestion of yellow phosphorus-containing fireworks. J Clin Gastroenterol 1995;21(2):139-142. DOI: 10.1097/00004836199509000-00015.

7. Mauskar A, Mehta K, Nagotkar L, Shanbag P. Acute hepatic failure due to yellow phosphorus ingestion. Indian J Pharmacol 2011;43(3):355356. DOI: 10.4103/0253-7613.81500.

8. Mohideen SK, Kumar KS. Should ratol paste be banned? Indian J Crit Care Med 2015;19(2):128-129. DOI: 10.4103/0972-5229.151026.

9. Seakins A, Robinson DS. Changes associated with the production of fatty livers by white phosphorus and by ethanol in the rat. Biochem J 1964;92(2):308-312. DOI: 10.1042/bj0920308.

10. Ghoshal AK, Porta EA, Hartroft WS. The role of lipoperoxidation in the pathogenesis of fatty livers induced by phosphorus poisoning in rats. Am J Pathol 1969;54(2):275-291.

11. Winek CL, Collom WD, Fusia EP. Yellow phosphorus ingestion: three fatal poisonings. Clin Toxicol 1973;6:541-545. DOI: 10.3109/15563657308991053.

12. Rubitsky HJ, Myerson RM. Acute phosphorus poisoning. Arch Intern Med 1949;83:164-178. DOI: 10.1001/archinte.1949.00220310047005.

13. Ravikanth R, Sandeep S, Philip B. Acute yellow phosphorus poisoning causing fulminant hepatic failure with parenchymal hemorrhages and contained duodenal perforation. Indian J Crit Care Med 2017;21(4):238-242. DOI: 10.4103/ijccm.IJCCM_410_16.

14. Simon FA, Pickering LK. Acute yellow phosphorus poisoning. "Smoking stool syndrome". JAMA 1976;235(13):1343-1344. DOI: 10.1001/jama.1976.03260390029021.
15. Santos O, Restrepo JC, Velásquez L, Castaño J, Correa G, Sepúlveda E, et al. Acute liver failure due to white phosphorus ingestion. Ann Hepatol 2009;8(2):162-165. DOI: 10.1016/S1665-2681(19)31799-5.

16. Nabi T, Nabi S, Rafiq N, Shah A. Role of N-acetylcysteine treatment in non-acetaminophen-induced acute liver failure: a prospective study. Saudi J Gastroenterol 2017;23(3):169-175. DOI: 10.4103/13193767.207711.

17. Squires RH, Dhawan A, Alonso E, Narkewicz MR, Shneider BL, Rodriguez-Baez N, et al. Intravenous nacetylcysteine in pediatric patients with nonacetaminophen acute liver failure: a placebocontrolled clinical trial. Hepatology 2013;57(4):1542-1549. DOI: 10.1002/hep.26001.

18. Bhat S, Kenchetty KP. N-acetyl cysteine in the management of rodenticide consumption - life saving? J Clin Diagn Res 2015;9(1):OC10-OC13. DOI: 10.7860/JCDR/2015/11484.5455.

19. Marin GA, Montoya CA, Sierra JL, Senior JR. Evaluation of corticosteroid and exchange-transfusion treatment of acute yellowphosphorus intoxication. N Engl J Med 1971;284(3):125-128. DOI: 10.1056/NEJM197101212840303.

20. Chugh SN, Pal R, Singh V, Seth S. Serial blood phosphine levels in acute aluminium phosphide poisoning. J Assoc Physicians India 1996;44(3):184-185.

21. Sogut O, Baysal Z, Ozdemir B. Acute pulmonary edema and cardiac failure due to zinc phosphide ingestion. J Emerg Med 2011;40(6): e117-e118. DOI: 10.1016/j.jemermed.2009.05.039.

22. Bumbrah GS, Krishan K, Kanchan T, Sharma M, Sodhi GS. Phosphide poisoning: a review of literature. Forensic Sci Int 2012;214:1-6. DOI: 10.1016/j.forsciint.2011.06.018.

23. Proudfoot AT. Aluminium and zinc phosphide poisoning. Clin Toxicol (Phila) 2009;47(2):89-100. DOI: 10.1080/15563650802520675.

24. Al-Azzawi MJ, Al-Hakkak ZS, Al-Adhami BW. In vitro inhibitory effects of phosphine on human and mouse serum cholinesterase. Toxicol Environ Chem 1990;29:53-56. DOI: 10.1080/02772249009357617.

25. Chugh SN, Jaggal KL, Sharma A, Arora B, Malhotra KC. Magnesium levels in acute cardiotoxicity due to aluminium phosphide poisoning. Indian J Med Res 1991;94:437-439.

26. Siwach SB, Singh P, Ahlawat S, Dua A, Sharma D. Serum and tissue magnesium content in patients of aluminium phosphide poisoning and critical evaluation of high dose magnesium sulphate therapy in reducing mortality. J Assoc Physicians India 1994;42(2): 107-110.

27. Goswami M, Bindal M, Sen P, Gupta SK, Avasthi R, Ram BK. Fat and oil inhibit phosphine release from aluminium phosphide - its clinical implication. Indian J Exp Biol 1994;32(9):647-649.

28. Shadnia S, Rahimi M, Pajoumand A, Rasouli M-H, Abdollahi M. Successful treatment of acute aluminium phosphide poisoning: possible benefit of coconut oil. Hum Exp Toxicol 2005;24(4):215-218. DOI: 10.1038/nrcardio.2017.172. [Epub ahead of print].

29. Mittra S, Peshin SS, Lall SB. Cholinesterase inhibition by aluminium phosphide poisoning in rats and effects of atropine and pralidoxime chloride. Acta Pharmacol Sin 2001;22(1):37-39.

30. Lim GB. Milestone 2: Warfarin: from rat poison to clinical use. Nat Rev Cardiol 2017. DOI: 10.1038/nrcardio.2017.172.

31. Deng Y, Qiu L. Therapeutic plasma exchange: a second-line treatment for brodifacoum poisoning following an anaphylactoid reaction to Vitamin K. Clin Case Rep 2016;5(1):35-38. DOI: 10.1002/ ccr3.756.

32. Patocka J, Petroianu G, Kuca K. Toxic potential of superwarfarin: brodifacoum. Mil Med Sci Lett 2013;82:32-38. DOI: 10.31482/ mmsl.2013.003.

33. (US), E.P.A. Reregistration Eligibility Decision (RED): rodenticide cluster 1998. [EPA738R-98-007].

34. King N, Tran M-H. Long-acting anticoagulant rodenticide (superwarfarin) poisoning: a review of its historical development, epidemiology, and clinical management. Transfus Med Rev 2015;29(4):250-258. DOI: 10.1016/j.tmrv.2015.06.002. 
35. Babcock J, Hartman K, Pedersen A, Murphy M, Alving B. Rodenticideinduced coagulopathy in a young child. A case of Munchausen syndrome by proxy. Am J Pediatr Hematol Oncol 1993;15(1):126-130. DOI: 10.1097/00043426-199302000-00021.

36. Ye L, Wang Z, Zhang H, Guo H, Guo Y, Chen L. Application of a new established system for toxic doses in children with 4-hydroxycoumarin rodenticide intoxication. Front Pediatr 2018;6:141. DOI: 10.3389/ fped.2018.00141.
37. Caravati EM, Erdman AR, Scharman EJ, Woolf AD, Chyka PA, Cobaugh DJ, et al. Long-acting anticoagulant rodenticide poisoning: an evidence-based consensus guideline for out-of-hospital management. Clin Toxicol 2007;45(1):1-22. DOI: 10.1080/15563650600795487.

38. Hellemans J, Vorlat $M$, Verstraete $M$. Survival time of prothrombin and factors VII, IX and X after completely synthesis blocking doses of coumarin derivatives. Br J Haematol 1963; 506-512. DOI: 10.1111/j.1365-2141.1963.tb05475.x. 